\title{
Surface Modifications of a Ti6Al4V Alloy by a Laser Shock Processing
}

\author{
M. Rozmus-GórnikOWsKA* \\ Faculty of Metals Engineering and Industrial Computer Science \\ AGH University of Science and Technology, 30 Mickiewicza Ave., 30-059 Cracow, Poland
}

\begin{abstract}
The influence of the Laser Shock Processing (LSP) on the morphology, microstructure and surface layer properties of a Ti6Al4V alloy has been studied. Residual stresses were assessed as well. For the Laser Shock Processing a $1 \mathrm{KW}$, high-power Q-switched Nd:YAG laser was used. During the process the surface of the investigated material was covered by series of single, partially overlapping impulses. The laser power density was a $1 \mathrm{GW} / \mathrm{cm}^{2}$ and a pulse duration of $18 \mathrm{~ns}$. The microstructure and the phases presented in the surface layer of the treated material were analysed by optical, scanning and transmisssion electron microscopy as well as by X-ray diffractometry. The X-ray diffractometry was also use to determine the residual stresses. It has been found that the laser shock processing can cause plastic deformation and generate the compressive residual stresses into the treated surface of a Ti6Al4V alloy.
\end{abstract}

PACS numbers: 68.37.-d, 68.35.bd, 68.35.Gy, 68.35.Ct

\section{Introduction}

Titanium alloys are widely used in many areas such as aircraft, military and biomedical engineering due to their excellent properties: high strength to weight ratio, low density, high corrosion resistance and good biocompatibility. Nevertheless, the application of these alloys under severe friction conditions is highly restricted due to their poor tribological properties such as high coefficient of friction and low hardness $[1,2]$. At the same time, from the alloy used as an implant material especially in the orthopedic fields, roughening of the surface is requirement [3].

One of the promising method of improvement the titanium alloys properties seems to be the laser shock processing (LSP), which allow to introduce strain hardening and compressive residual stress into the treated surface layer [4]. Additionally, the laser shock processing allow to control the roughness surface of the material.

Laser shock processing is a new surface treatment which was originally developed at the Battelle Columbus Labolatory in the 1970s [5, 6]. The principle of LSP is to use a high intensity laser and suitable overlays to generate high pressure shock waves on the surface of the treated material. When a material is irradiated with a $\mathrm{Q}$ switched impulse laser, operated at power density greater than $0.1 \mathrm{GW} / \mathrm{cm}^{2}$, a shock wave can be generated. Surface of the treated material, before LSP can be coated with a black paint, as a laser energy absorbing layer and covered with a transparent layer (for example water or glass) (Fig. 1a). When the laser beam strikes the coated sample, the black paint, due to absorption of laser beam

\footnotetext{
* e-mail: rozmus@agh.edu.pl
}

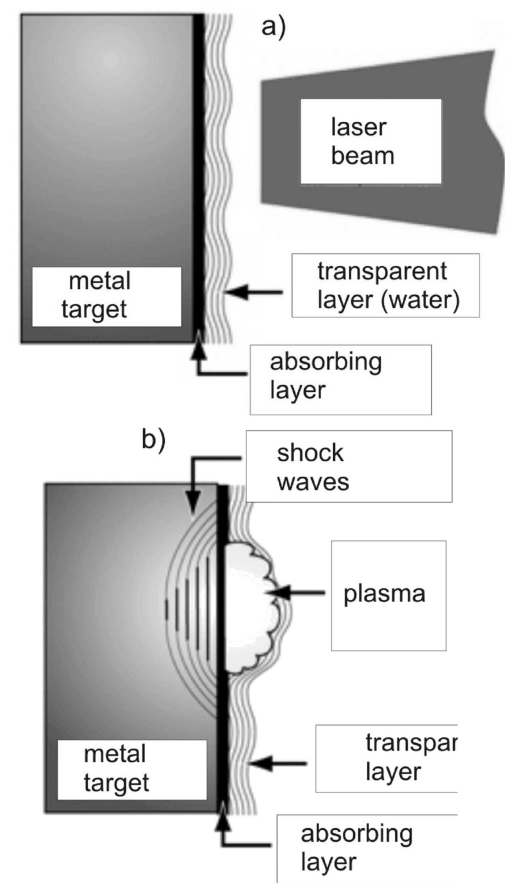

Fig. 1. Schematic representation of the laser shock processing (a) metal target with absorbing and water layers (b) shock wave generation by laser beam.

energy, is heated and instantaneously vaporized. The vapor absorbs the remaining laser beam radiation and produces plasma (Fig. 1b). The rapidly expanding plasma creates a high surface pressure, which propagates into material as a shock wave. The shock wave can induces compressive residual stress that penetrates beneath the surface and strengthens the surface of the treated mate- 
rial. By using a material that is transparent to the laser beam, the expansion of this hot plasma can be delayed compared to the free expansion that occurs in direct ablation, and thus the magnitude of the pressure can be controlled [7]. This effect may induce microstructural changes, cause high increase dislocations density, influence on roughness surface of the material as well as introduce a compressive residual stresses into the treated surface of the material [8].

The aim of this work was to investigate the influence of the LSP process on the morphology, microstructure and surface layer properties of a Ti6Al4V alloy. Residual stresses were assessed as well.

\section{Materials and experimental procedures}

Experiments were performed on Ti6Al4V alloy in the form of disk with $16 \mathrm{~mm}$ diameter and $8 \mathrm{~mm}$ thick, cut from the rod. The chemical composition of the investigated Ti6Al4V titanium alloy is listed in Table I. Before the LSP process, the surface of the investigated material was mechanically grounded and polished, and then coated with the $50 \mu \mathrm{m}$ black paint and covered with $3 \mathrm{~mm}$ thick layer of water. The laser used for LSP process was a $1 \mathrm{KW}$, high power Q-switched Nd:YAG laser, operating at $1.064 \mu \mathrm{m}$ wavelength, with a laser power density of $1 \mathrm{GW} / \mathrm{cm}^{2}$ and a puls duration of $18 \mathrm{~ns}$. The process was performed in an air atmosphere. During the laser shot processing the rectangular area of the disk $(10 \mathrm{~mm} \times 3.5 \mathrm{~mm})$ was covered by the series of singles and partially overlapping spots (Fig. 2). The diameter of the laser beam on the sample was $2 \mathrm{~mm}$.

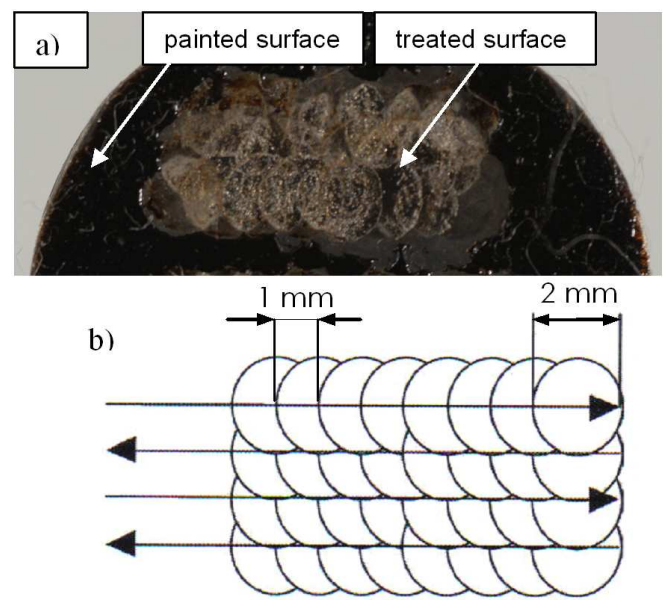

Fig. 2. Optical image showing the treated sample (a) and scheme of the treated area (b).

Microstructure of the material before treatment was characterized by Scanning Electron Microscopy (SEM, Hitachi $\mathrm{S}-3500 \mathrm{~N}$ ) with utilization of the $Z$ contrast produced by backscattered electrons (SEM BSE). The morphology of the laser treated surface as well as cross section of the treated zone were examined by scanning
TABLE I

Chemical composition of Ti6Al4V titanium alloy (mass \%).

\begin{tabular}{c|c|c|c|c|c}
\hline \hline Element & $\mathrm{Al}$ & $\mathrm{V}$ & $\mathrm{Fe}$ & $\mathrm{C}$ & $\mathrm{Ti}$ \\
\hline Mass rate & $6.1 \%$ & $4.3 \%$ & $0.17 \%$ & $0.01 \%$ & balance
\end{tabular}

electron microscopy, using the signal from the secondary emission electrons (SEM SE). The roughness of the surface was measured by TOPO-L50 equipment.

In order to identify the existing phases in the surface layer of the material after laser treatment, the X-ray phases analysis (XRD, D8 Discover Bruker) with $\mathrm{CuK}_{\alpha}$ was used. Also the residual stresses in the treated surface of the Ti6Al4V alloy were determined by means of a XRD method. Measurements were made employing a grazing angle $\left(\sin ^{2} \psi\right)$ technique. Using this method, the stress can be measured at very small depths of the order of a few $\mu \mathrm{m}$ [10]. The measurements were performed using $\mathrm{CuK}_{\alpha}$ radiation $(\lambda=0.15406 \mathrm{~nm})$. The experiment was repeated for various incidence angles $\alpha$ corresponding to different penetration depths $t$ (Table II).

TABLE II

Result of the in-depth residual stress measurements.

\begin{tabular}{c|c|c}
\hline \hline $\begin{array}{c}\text { Incidence } \\
\text { angle }\left[^{\circ}\right]\end{array}$ & $\begin{array}{c}\text { Penetration } \\
\text { depth }[\mu \mathrm{m}]\end{array}$ & $\begin{array}{c}\text { Stresses } \\
{[\mathrm{MPa}]}\end{array}$ \\
\hline $3^{\circ}$ & 1.6 & -431 \\
$12^{\circ}$ & 5.1 & 459 \\
$26.7^{\circ}$ & 7.2 & 435
\end{tabular}

Detailed microstructural investigation of modified surface layer was carried out by Transmission Electron Microscopy (TEM, Philips CM20). Thin foils were cut perpendicular to the treated surface and prepared using FEI focused ion beam (FIB) Quanta 3d system.

\section{Results and discussions}

Scanning Electron Microscopy investigations of the Ti6Al4V alloy before the laser treatment showed that this alloy before laser treatment had a homogeneous microstructure with very fine grains of $\alpha$ and $\beta$ phases (Fig. 3).

SEM investigations of the treated surface proved that the laser shot processing caused an ablation and melting of thin surface layer of the treated alloy. The rapid heating and melting accompanied with a high pressure of plasma caused that the liquid metal spilled from the central part of the treated area towards the periphery, where due to cooling, has been frozen (Fig. 4a). The melted features most observed on the surface after LSP were craters, holes, solidified droplets, splash-like spills and molten flowing layers. It was found that the central part of the treated area contain some craks (Fig. 4b), whereas 


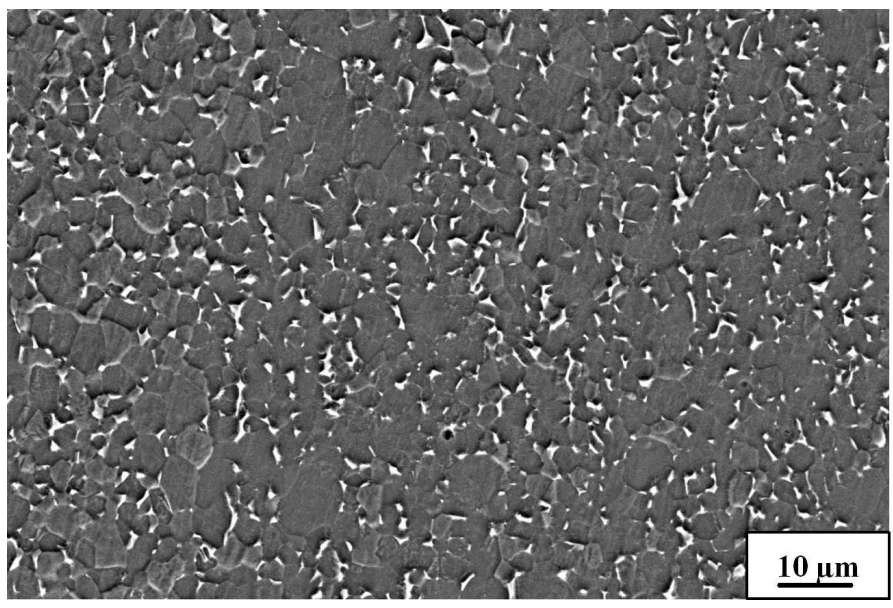

Fig. 3. The microstructure of the Ti6Al4V alloy before the laser treatment (SEM BSE).

the periphery of the treated area (Fig. 4a) was only folded and was free of cracks. Finally, the SEM investigations indicated that the process of the laser shot processing was not purely mechanical but rather a thermo-mechanical process.

The measurements of the surface roughness revealed that due to ablation and melting, considerably the roughness of the surface increased compared to the roughness of the surface before treatment. $R_{\mathrm{a}}$ (arithmetic average of the absolute values of all points of the profile) increased from $0.1 \mu \mathrm{m}$ before treatment to $0.82 \mu \mathrm{m}$ after laser irradiation. The analysis of the surface after laser treatment with profilometer is presented in Fig. 5. The increase of the roughness surface of the Ti6Al4V alloy due to laser treatment indicate that the laser shot processing could be used after elimination of cracks as a method of increasing the surface roughness area of an implant.

The X-ray diffraction profile of near surface region of the treated area is given in Fig. 6. It was found that surface layer of the Ti6Al4V alloy after LSP was composed mainly of martensite $\left(\alpha^{\prime}\right)$.

The Table II shows a result of the in-depth residual stress measurements. The residual stress in the treated surface measured at a depth of $1.6 \mu \mathrm{m}$ was compressive $(-470 \mathrm{MPa})$, while measured at a depth of $5.1 \mu \mathrm{m}$ and $7.1 \mu \mathrm{m}$ were tensile (459 $\mathrm{MPa}$ and $435 \mathrm{MPa}$ respectively). The presence of compressive stresses in the near surface region $(1.6 \mu \mathrm{m})$ indicate that the laser shock processing can generate the compressive residual stressess into the Ti6Al4V alloy.

Microstructure of thin foils from surface layer are presented in Fig. 7. This micrographs showed that LSP process performed under the conditions of $1 \mathrm{GW} / \mathrm{cm}^{2}$ laser power density and puls duration of $18 \mathrm{~ns}$ resulted in formation of the surface layer composed of three well defined zones: external - oxidized with cracks, central zone - martensitic and internal - deformed, with high dislocation density level. The thickness of the second
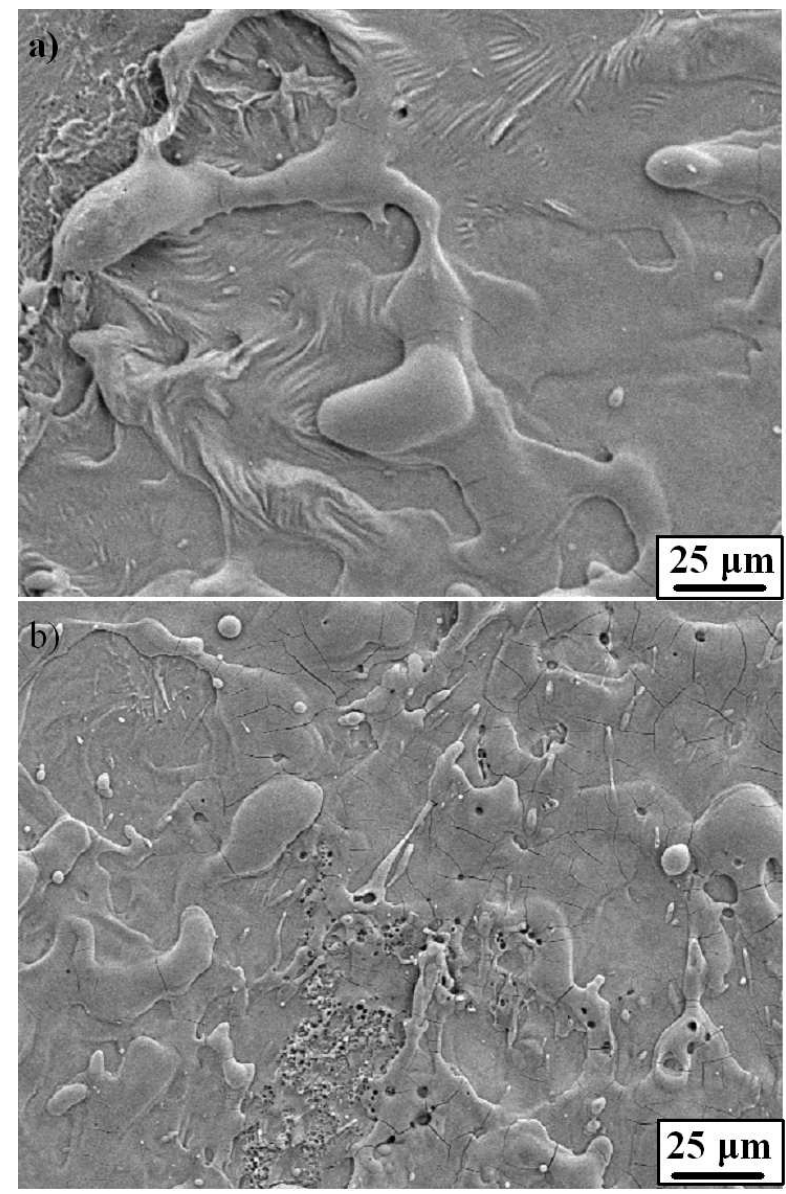

Fig. 4. Topography of the Ti6Al4V alloy after LSP process (SEM SE); the near periphery (a), the center of the spot (b).

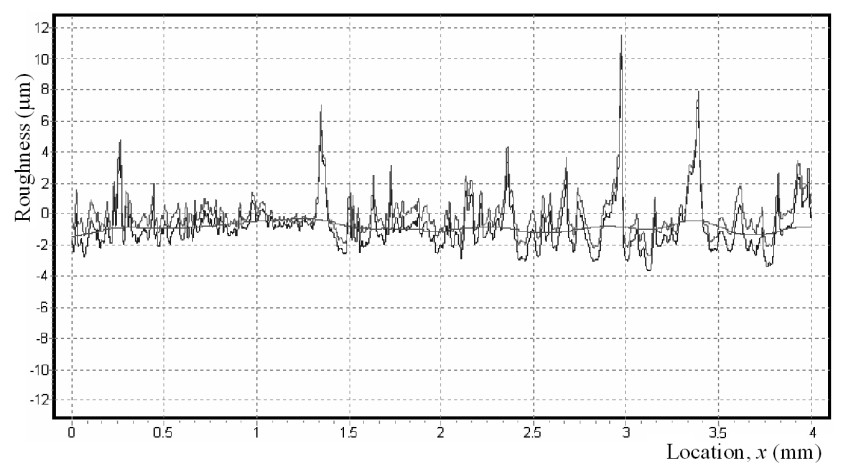

Fig. 5. Surface roughness profile of the treated area.

martensitic zone varied between 1-2 $\mu \mathrm{m}$. During laser processing, the material in this zone was heated up to the temperature range where $\beta$ phase is present in Ti6Al4V alloy. Due to the rapid cooling, after laser processing $\beta$ phase transformed to the $\alpha^{\prime}$ martensite phase. The third zone - of the deformed material contains grains with high dislocation density and slip bends. 


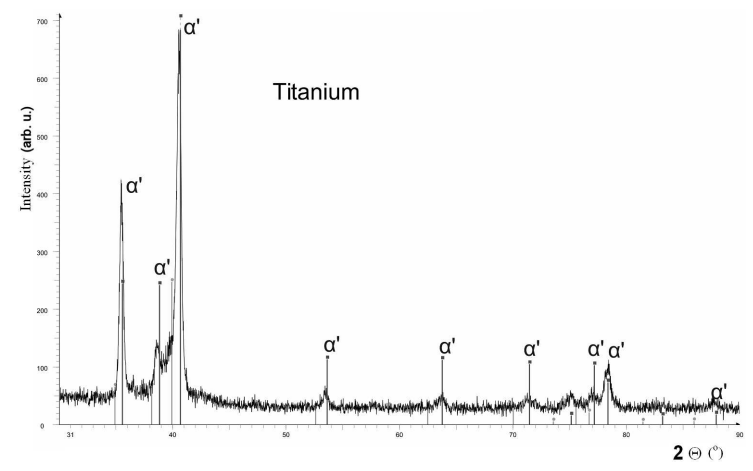

Fig. 6. XRD pattern of Ti6Al4V titanium alloy after LSP.
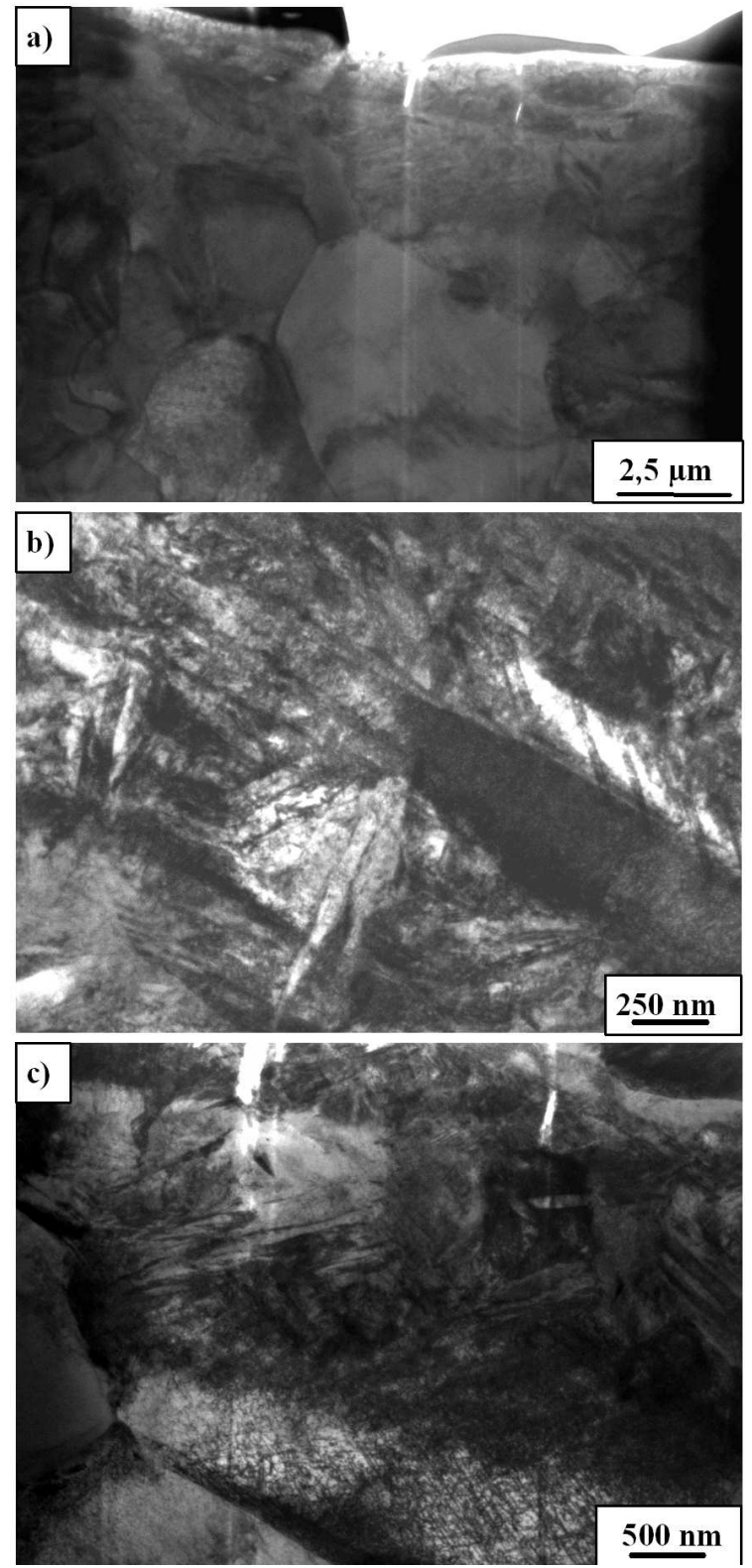

Fig. 7. Typical TEM microstructure of the Ti6Al4V titanium alloy after 1 laser pulse.

\section{Conclusions}

- It was found that the laser shock processing performed under the conditions of $1 \mathrm{GW} / \mathrm{cm}^{2}$ laser power density and puls duration of $18 \mathrm{~ns}$ was not purely mechanical but rather a thermo-mechanical process. The melted features most observed on the surface after LSP were craters, holes, solidified droplets, splash-like spills and molten flowing layers.

- The measurements of the surface roughness indicate that the LSP process increased the roughness surface of the treated material.

- It was found that the laser shock processing can cause plastic deformation and generate the compressive residual stresses into the Ti6Al4V alloy.

\section{Acknowledgments}

The investigations presented in this paper were financially supported by the Ministry of Science and Higher Education under contract nr: N N507 354135. The author would like to acknowledge Prof. Jan Kusinski and Prof. Marek Blicharski from the AGH University of Science and Technology in Krakow for their useful discussion and remarks and Prof. Jan Marczak from the Military University of Technology for the laser shot peening of the samples.

\section{References}

[1] N. Tsuji, S. Tanaka, T. Takasugi, Surf. Coat. Technol. 203, 1400 (2009).

[2] Y.S. Tian, Cz. Chen, S.T. Li, Q.H. Huo, Appl. Surf. Sci. 242, 177 (2005).

[3] A. Gaggl, G. Schultes, W.D. Muller, H. Kacher, Biomaterials 21, 1067 (2000).

[4] P. Peyre, C. Carboni, P. Forget, G. Beranger, C. Lemaitre, D. Stuart, J. Mater. Sci. 42, 6866 (2007).

[5] M. Morales, J.L. Ocana, C. Molpeceres, J.A. Porro, A. Garcia-Beltran, Surf. Coat. Technol. 202, 2257 (2008).

[6] J.M. Yang, Y. C Her, N. Han, A. Clauer, Materials Science and Engineering A 298, 296 (2001).

[7] A. Kruusing, Opt. Lasers Eng. 41, 307 (2004).

[8] G. Gomez-Rosas, C. Rubio-Gonzalez, J.L. Ocana, C. Molpeceres, J.A. Porro, W. Chi-Moreno, M. Morale, Appl. Surf. Sci. 252, 883 (2005).

[9] H.B. Sencer, S.A. Maloy, G.T. Gray III, Acta Materialia 53, 3293 (2005).

[10] S. Wroński, K. Wierzbanowski, A. Baczmański, CH. Braham, A. Lodini, Archives of Metallurgy and Materiale 53, 276 (2008). 